20

\title{
Is Strategic Development of Leadership Capacity for the Higher Education Workplace Possible?
}

\author{
Majorie Angel Brown \\ University of Toronto
}

Beginning graduate students who are working in higher education can benefit from establishing a professional development plan designed to enhance leadership capacity. The challenge is to align personal goals with those of the graduate program, yet ensure that collegial socialization and professional competency development occurs. Professional socialization refers to the acquisition of values, attitudes, skills, and competencies pertaining to a professional subculture. In this paper, I describe an activity I designed and the process I used that address equity, diversity, and inclusion as one professional competency area in my socialization process as a strategy to become a more effective leader.

\section{Introduction}

G raduate student socialization is a process of $\mathbf{I}$ "voluntarily learning new and different sets of attitudes, values, and behaviours from those in my background and previous experiences for the purpose of integrating the new professional role into my identity" (Weidman, Twale, \& Stein, 2001, p. 6). I am seeking involvement and investment by faculty in my Ph.D. program, as recommended by Thornton and Nardi (cited in Weidman, Twale, \& Stein, 2001), that Black women Administrators and indigenous scholars write about as missing in their experiences (Byrd, 2009; Henry \& Tator, 2009; Lewis \& Bush, 2010). These recommended experiences include clear, realistic guidelines, collaborative dialogue, and formal mentoring roles (Cress, 2008; Freese \& Strong, 2008; Mighty, Ouelett, \& Stanley, 2010).

\section{Equity, Diversity, and Inclusive Excellence (EDI) for Socialization}

As I began a new journey embarking on a Ph.D. at the Ontario Institute for Studies in Education/ University of Toronto, I wanted to maximize opportunities to develop my competence within a framework of professional socialization. I reviewed the report Professional Competency Areas for Student Affairs Practitioners, which was developed by a joint task force comprised of members of College Student Educators International (ACPA), and Student Affairs 
Administrators in Higher Education (NASPA), and finalized July 24, 2010. While the profession as described by the document is prevalent in the United States, and the report is intended primarily for that audience, I am a member of both associations and subscribe to the learning outcomes for my own skill and role development.

The competencies outlined were developed and endorsed by both organizations. They are listed with a description first, and then several categories of expected learning and skill development for each of basic, intermediate, and advanced levels. The intention is for student affairs practitioners to examine themselves and devise a strategy to develop capacity, and to practice the necessary attributes outlined. I designed a profile for myself that will serve me for years to come as I continue to grow and learn. I expect this profile to evolve during each year of the Ph.D. as I adjust and become transformed, and set objectives in all competency areas and within each level.

Each competency area begins with a description, and each has three levels: basic, intermediate, and advanced. The 10 competency areas are listed below:

\section{Advising and Helping}

2. Assessment, Evaluation, and Research

3. Equity, Diversity, and Inclusion

4. Ethical Professional Practice

5. History, Philosophy, and Values

6. Human and Organizational Resources

7. Law, Policy, and Governance

8. Leadership

9. Personal Foundations

10. Student Learning and Development

Equity, Diversity, and Inclusion (EDI) is the third of the ten competencies, and is described as "the knowledge, skills, and attitudes needed to create learning environments that are enriched with diverse views and people. It is also designed to create an institutional ethos that accepts and celebrates differences among people, helping to free them of any misconceptions and prejudices" (ACPA/NASPA, 2010, p.10). Each competency has several levels.
Below is a statement from each of the three EDI levels:

Basic - one should be able to assess and address one's own awareness of EDI, and articulate one's own differences and similarities with others.

Intermediate - one should be able to identify systemic barriers to equality and inclusiveness, and then advocate for and implement means of dismantling them.

Advanced - one should be able to provide leadership in fostering an institutional culture that supports the free and open exchange of ideas and beliefs, and where issues of power and privilege are identified and addressed (p.10-11)

\section{How to Improve Practice of Educators}

During my session at the Society for Teaching and Learning in Higher Education (STLHE) Conference in June 2011, I used the above EDI basic competency as an example to demonstrate how I assess my own awareness on a regular basis. The participants then de-briefed how and when they could do the same in their various roles on their own campuses. I disclosed that I wanted to grow and I explained I was following the recommendations of those who have gone before me. Guido-DiBrito and Chavez (2003) explain, that "as educators, we bring our own strongly imprinted sets of norms, values, behaviours, and assumptions into learning environments as well [as our students]. Ongoing reflection and self-analysis of the daily influence of these cultural aspects is essential for higher education and student affairs educators to be effective in creating multiculturally competent learning environments" (p. 18).

This particular activity was an adaptation 
of a process described as a means to consider how to "value the other," from Chavez, Guido-DiBrito, and Mallory (2003). The authors encourage readers to follow these steps: create a pie by drawing a large circle on a piece of paper; divide the circle by drawing lines from one side of the circle to the other until four to eight pieces of pie are represented; label each piece of pie with social identities; consider the level of awareness at the 'affective, behavioural, and cognitive' levels of understanding; and fill in the pie chart to create a map of the current state of awareness. If I complete this exercise on a regular basis and keep the dated results, I will be able to see changes when comparing levels of awareness over time, becoming more competent in valuing diversity in myself and others. The key is to use an intersectional approach when I consider my many social selves as well as my personal ethnic identity.

I strive then to use my awareness to improve my practice, seek out diverse experiences, and become consciously aware of the meaning of these experiences through critical self-reflection. As Ford and Dillard (1996) explain, "the process of becoming multicultural is a recursive cycle of deconstructing self as object, reconstructing self as subject, and engaging in subjectto-subject relations with others" (p. 237). Engaging in this self-reflective exercise is one way to begin the cycle to develop EDI knowledge, skills, and attitudes.

\section{Why Must I Be Intentional and Self- Reflexive?}

There is evidence from scholars, researchers, and administrators in the United States and Canada that suggest the discourses of inclusion, and attention to attracting and retaining historically underrepresented graduate students serve a neo-liberal agenda that does not really support social justice and equity (Byrd, 2009; Cress, 2008; Mighty, 1991; Siegel, 2006). Further, for a Black woman like me to work in higher education, I must be prepared to deal with pervasive and systemic racism and sexism (Henry \& Tator, 2009; Lewis \& Bush, 2010). Pope, Reynolds, and Mueller (2004) point out that "[today] one's ability to engage in deeply multicultural practices and pedagogies is no longer constrained to one's membership in the group served and is the daily responsibility of every educator" ( $\mathrm{p}$. 18). As a racialized person and someone marginalized on multiple dimensions, I therefore need to be intentional about my own development.

In an effort to arm myself with the tools needed to face the reality described by scholars, I decided to examine my assumptions about higher education, access, equity, diversity, and inclusive excellence. I identified four areas in which to begin my self-assessment before applying to the Ph.D. program:

1. my ability to deal with the implementation of rules and regulations, or red tape

2. the program requirements

3. my own personal effectiveness and learning needs as a professional working in the higher education environment with no plans of becoming a professor

4. theories about professional socialization as a graduate student

My evaluation of the outcome from this reflection is outside the scope of this paper. However, an analysis of my skills, lead to a positive decision to boldly begin this journey because I wanted to become a more influential leader and contribute to organizational effectiveness. Berman (2006) suggests that organizational effectiveness refers to both outcome and output measures - outputs are "the immediate results of organization activities" and outcomes are "measures of the extent that the organization attains their goals or ultimate purposes" (p. 6). By the same extent student or employee effectiveness would refer to immediate results of my planned activities as outputs, and my outcomes would be the measures of the extent to which I attain my goals aligned with the program or organization. This is the approach I usually take in preparing my professional development plan. However, in 2009, I also included a review of my intercultural maturity (King \& Baxter Magolda, 2005), in light 
of the ten competency areas in order to highlight my capacity to deal with the structure and culture of a public organization. Bozeman (2000) defines red tape as ineffective and excessive rules, regulations, and procedures that "do not advance the legitimate purpose the rules were intended to serve" and reduce organizational performance and effectiveness (p. 12). Before returning to university student mode, I wanted to check that I was willing and ready to work with others in a prescribed program, and prepare myself for the inevitable red tape of the application process and other procedural needs of each area of the university bureaucracy.

\section{Summary}

I made the decision to socialize myself as a graduate student before applying to graduate school. Scholars indicate that personal changes begin to occur before entering the graduate student environment; I looked to my professional associations, family, and other supports to provide well-balanced approaches to managing the inevitable changes that would take place. In preparation for the inevitable change, and as a result of my self-assessment, I organized a chart and reflective journal to address each of the years recommended for my Ph.D. program. My decision to focus on one professional competency in the paper, Equity, Diversity, and Inclusion, was motivated by a desire to integrate my learning with practice. The method I used was to draw upon the research and theories of scholars working in higher education and student affairs. I examined myself, reflected upon my findings, and created an integrated chart and other tools to aid in tracking my progress. So far, my strategy has helped to highlight areas for improvement in my practice as I continue to build leadership capacity.

\section{References}

ACPA/NASPA. (2010). Professional competencies and standards. Washington, DC: Joint Task Force of ACPA and NASPA Educators \& Student Affairs Professionals in Higher Education.
Berman, E. (2006). Performance and productivity in public and nonprofit organizations. Armonk, New York: M.E. Sharpe.

Bozeman, B. (2000). Bureaucracy and red tape. Upper Saddle River, NJ: Prentice Hall.

Byrd, M. (2009). Telling our stories of leadership: If we don't tell them they won't be told. Advances in Developing Human Resources, 11(5), 582-605.

Chavez, A., Guido-DiBrito, F., \& Mallory, S. (2003). Learning to value the 'other:' A model of diversity development. Journal of College Student Development, 44(4), 1-17.

Cress, C. (2008). Creating inclusive learning communities: The role of student-faculty relationships in mitigating negative campus climate. Learning Inquiry, 2, 95-111.

Ford, T. \& Dillard, C. (1996). Becoming multicultural: A recursive process of self-and social construction. Theory into Practice, 35(4), 232-238.

Freese, A., \& Strong, A. (2008). Establishing a learning community as a site to explore our multicultural selves. In. A.P. Samaras et al. (Eds.), Learning communities in practice (pp. 103-116). Springer Science and Business Media.

Guido-DiBrito, F. \& Chavez, A. (2003). Understanding the ethnic self: Learning and teaching in a multicultural world, Journal of Student Affairs, 12, 11-21.

Henry, F. \& Tator, C. (Eds.). (2009). Racism in the Canadian university: Demanding social justice, inclusion, and equity. Toronto, ON: University of Toronto Press.

King, P. \& Baxter Magolda, M. (2005). A developmental model of intercultural 
maturity. Journal of College Student Development, 46(6), 571-592.

Lewis, C. \& Bush, V. (Eds.). (2010). Intersections: Race, gender, organizational culture and leadership. Sterling, VA: Stylus Publishing.

Mighty, J., Ouelett, M., \& Stanley, C. (2010). Unheard voices among faculty developers. New Directions for Teaching and Learning, 122, 103-112.

Mighty, J. (1991). Valuing workforce diversity: A model of organizational change. Canadian Journal of Administrative Sciences/Revue canadienne des sciences de l'administration RCSA/CJAS, 8(2), 64-70.

Pope, R., Reynolds, A., \& Mueller, J. (2004). Multicultural competence in student affairs. San Francisco: Jossey-Bass.

Siegel, D. (2006). Organizational response to the demand and expectation for diversity. Higher Education, 52, 465-486.

Weidman, J., Twale, D., \& Stein, E. (2001). Socialization of graduate and professional students in higher education. ASHE-ERIC Higher Education Report, 28(3). San Francisco: JosseyBass.

\section{Biography}

Majorie Angel Brown is a Ph.D. Candidate in the Department of Leadership, Higher, and Adult Education of Ontario Institute for Studies in Education (OISE) and the University of Toronto. Her research interests are related to the strategic development ofleadership capacity; student transition and engagement; and organizational development of higher education workplaces for equity, diversity, and inclusive excellence. 